\title{
Analysis on the Marketing Strategy of Hermes
}

\author{
Yihan Wang ${ }^{1}$ \\ ${ }^{1}$ Dalian Maple Leaf International School, Location of school: Dalian, China \\ Email:1278948150@qq.com
}

\begin{abstract}
The success of Hermes as the world's largest luxury jewelry brand depends in large part on its proper marketing strategy. This paper will analyze Hermes' marketing strategy in terms of product, price, sales channels and marketing techniques according to the $4 \mathrm{p}$ model. Hermes has ensured its high-end status by the workmanship of its products and limited its target sales group with its smart pricing. Since the brand has achieved the purpose of proving its status against the upper class of society, it is known as a product sought after by the upper class even though it is expensive. Hermes did little to advertise its products, but was able to maintain a steady flow of sales, which helped it successfully save money on publicity.
\end{abstract}

Keywords: Hermes, $4 p$ model, Luxury brand, Marketing strategy

\section{INTRODUCTION}

Hermès is a famous French luxury brand, established in France in 1837, started as a seller of fine horse harnesses. 1900, Hermès launched its first travel bag, introducing its premium travel bag, followed by a series of high quality stitched leather riding accessories that began to gain popularity. This was followed by a series of iconic Hermès items, especially its handbags and scarves. Hermes, as a family business, has been passed down and developed through several generations of its family, eventually becoming one of the most popular and largest luxury brands in the world. At the same time, the marketing strategy of its products is unique due to the manufacturing and pricing of its products themselves and has supported the success of its business to become a brand that has become a global sensation. Therefore, it is worthwhile to study the factors that have made the company so successful, and this paper will analyze Hermes' marketing strategy using the $4 \mathrm{p}$ model. The four strategies of product, price, place and promotion are analyzed separately to derive its successful marketing strategy.

\section{PRODUCT}

Hermes' main product is handbag, and its products use a very precious raw material - leather. For most of Hermes' goods, leather is an essential part. Leather and genuine leather both belong to animal fur, but the difference is that leather is the product of several physical and chemical processes using animal skin. Therefore, due to the complex process, the overall leather material is also more precious. The leather used by Hermes includes lizard skin, ostrich skin, alligator skin, calfskin, etc., all of which are expensive raw materials for making bags. Hermes in the major stars and rich people sought after two handbags are Parkin bag and Kelly bag. Togo leather made from calf is a very popular luxury leather bag, and for good reason. Togo holds its shape well, it is scratch resistant and can be refurbished to new condition. The Parkin and Kelly bags are made of this leather and the inside of the bag is lined with goatskin. These bags are not as durable as other bags.

Water stains and scratches are more visible on this type of bag. An artisan makes up to 3-4 bags per week, and each bag is made by the artisan after a long period of careful sewing. It takes an expert artisan 40 hours to make a Parkin bag. The saddle stitch, which is the basis of the brand's reputation, cannot be replicated by machine; only two needles passing through the same stitch at the same time can correctly sew a Parkin bag. If done correctly, the saddle stitch will never come apart either on the saddle or on the Parkin bag. Because the materials used to make them are rare, high quality and durable, Hermès bags can withstand the test of events.

The entire Hermes production is limited to no more than 15 bags per month, and this long production process determines its rarity and also greatly affects its price. To buy a Hermes bag is not like other luxury 
jewelry brands, ordinary models can directly get the spot at the counter, only high order models and limited models need to wait for custom, but even if you wait, from time to time will not exceed a year. However, Hermes has strict rules about who can get their iconic bags. There is a long waiting list that can extend up to 6 years. Even getting on the waiting list is difficult because the ranking of customers depends on previous

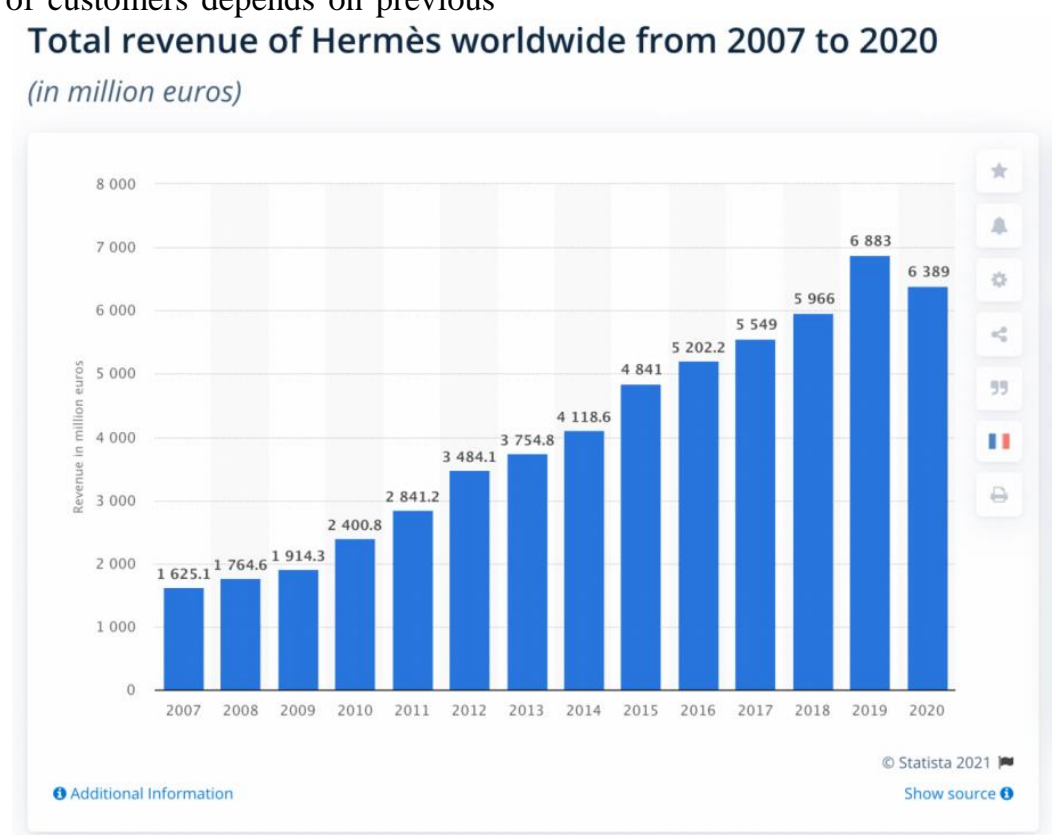

purchases and the reputation of the company. Therefore, there is no guarantee that you will be placed on the waiting list in the first place. Figure 1 shows the total revenue of Hermes Company from 2007 to 2009, and it continues to rise. By 2020, the total revenue was 494 million euros less than the 2019 revenue due to the epidemic.

Figure 1. Total revenue of Hermès worldwide from 2007 to 2020 [8]

\section{PRICING}

Hermes' pricing has chosen its audience for it and indicates its product positioning. Hermes handbags can be described as sky-high, and the people they are aimed at are the top of society, but their handbags are still sought after by people from all walks of life and have become the ultimate dream of many girls. In fact, compared to other luxury brands, Hermes handbag design is not exactly suitable for people under 30 years old. The main design style of Hermes handbags is atmospheric, simple and noble, which may not exactly match the young image of people under 30 years old as well as their fashion pursuits. Also, few people under 30 can afford to buy most Hermes handbags or other products, so the under 30 group is not its main sales group either. With such a high price tag, the main reason for the high status of Hermes handbags is not the design, materials or production, but more the impact the brand has had on people. Nowadays, the term Hermes and its products are more synonymous with status, which symbolizes a person's level of consumption and social status. Many wives of luxury families use Hermes handbags as an indispensable accessory and as a standard by which they define others.

"A basic Birkin costs $\$ 800$ to manufacture, and the most expensive sold for in excess of $\$ 300,000 . "$
Through this data, We can see that although the cost of Hermes handbags is high compared to other brands, the difference is huge compared to its selling price. For the time being, not counting the cost of sales such as transportation, stores and staff salaries, the profit can reach $99.73 \%$. At the same time as mentioned above Hermes is not like other luxury brands that can get the bag directly in the store spot, basically need to customize the appointment, in the store can only pick the color and material and other details of the bag, many regular customers will choose to book in the official website or call the special line to order, which also reduces the cost of its stores.

Hermes, as a luxury brand, has adopted a premium pricing strategy. This pricing strategy creates an aura of luxury, exclusivity or higher quality by artificially inflating the price.

- Higher prices mean higher quality

Typically, products are priced based on cost, and priced in a way that ensures sales and profits. Therefore, when pricing is high, the value of the item itself will be correspondingly high.

\section{- Raising customer curiosity}

When a product is priced many or even several times more than a similar product, changing the pricing will 
attract the curiosity of customers to try to buy the product.

\section{- Enhancing rarity}

Hermes handbags are well controlled in terms of rarity, and because they are expensive, companies choose to increase the rarity and raise the price. This not only reduces consumption, but also makes the brand known for its rarity, luxury, and represents luxury.

- No discounts

Unlike other brands, Hermes does not have discounts regardless of the occasion or situation.
- Satisfy the exclusivity psychology of luxury goods buyers

A large part of the reason for customers to buy luxury goods comes from the pursuit of exclusivity. Everyone wants to have a unique and exclusive item.

- Haute couture and high price can meet the exclusivity psychology of consumers.

Figure 2 shows the revenue as well as cash flow trends of Hermes from 2007 to 2017. The figure shows that all revenues and cash flows are on a steady upward trend.

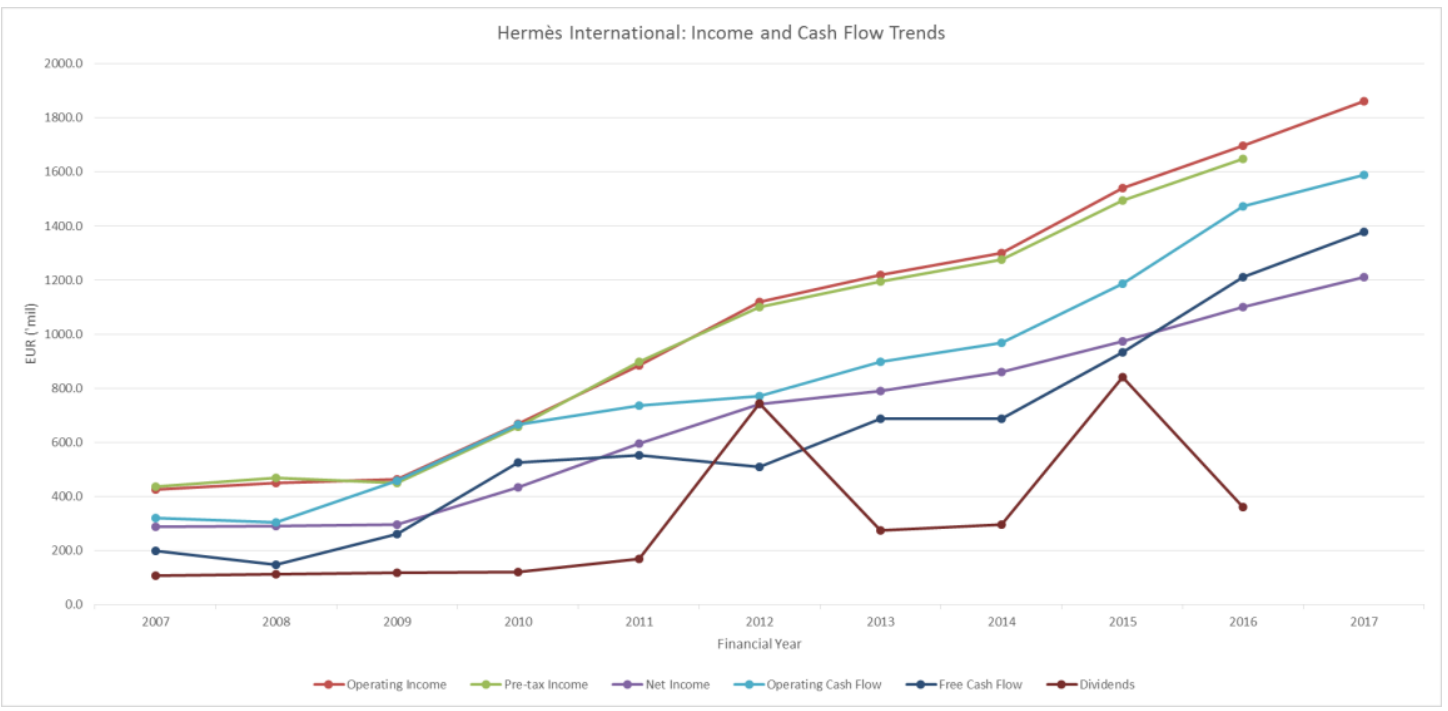

Figure 2 . Hermes International: Income and Cash Flow Treands[14]

\section{SALES CHANNELS}

Hermes adopts an omnichannel strategy, developing multi-channel distribution and thus establishing a multi-channel sales system.

\subsection{Online Channels}

Online sales are a good channel to develop the business, "... Hermès... While revenues dropped by 25 percent from $€ 3.3$ billion ( $\$ 3.9$ billion) to $€ 2.5$ billion... the growth of its online channels, where sales continued to rise even as its stores reopened." We can see that the definition of Hermès' online sales is not just Hermès' definition of online sales is not just a replacement for offline stores, but rather another major sales platform. Hermes has invested heavily in building its online sales platform, and while sales have declined in the face of the epidemic's inability to open its stores, purchases from online sales have continued to rise. What helped it achieve online success was ".... . down to how the company viewed - since the beginning some years ago its digital offering as complementary to its core business, rather than a threat, said Mario Ortelli, managing partner at luxury advisors Ortelli\&Co. Hermès is not averse to new online sales, and sees them as an alternative channel that can be developed. The success of an online sales platform is not achieved in a short period of time, it takes years and years of building and practice. Hermes was able to develop its online sales channel as a stand-alone channel because it realized the importance of the online platform early on and actively developed it. Due to the rapid development of the online sales channel, Hermes' logistics.

\subsection{Entity Store Sales}

At the same time, Hermès has entity stores all over the world, in 45 countries, with a total of 331 stores, as shown in figure 3. Its main markets are Asia Pacific, Europe, Japan and the United States, which has helped it to become the world's largest luxury jewelry brand. Hermes promotes its brand through the establishment of stores worldwide. Figure 3 shows the distribution of Hermes stores around the world, with major distribution areas in Europe and Asia. 


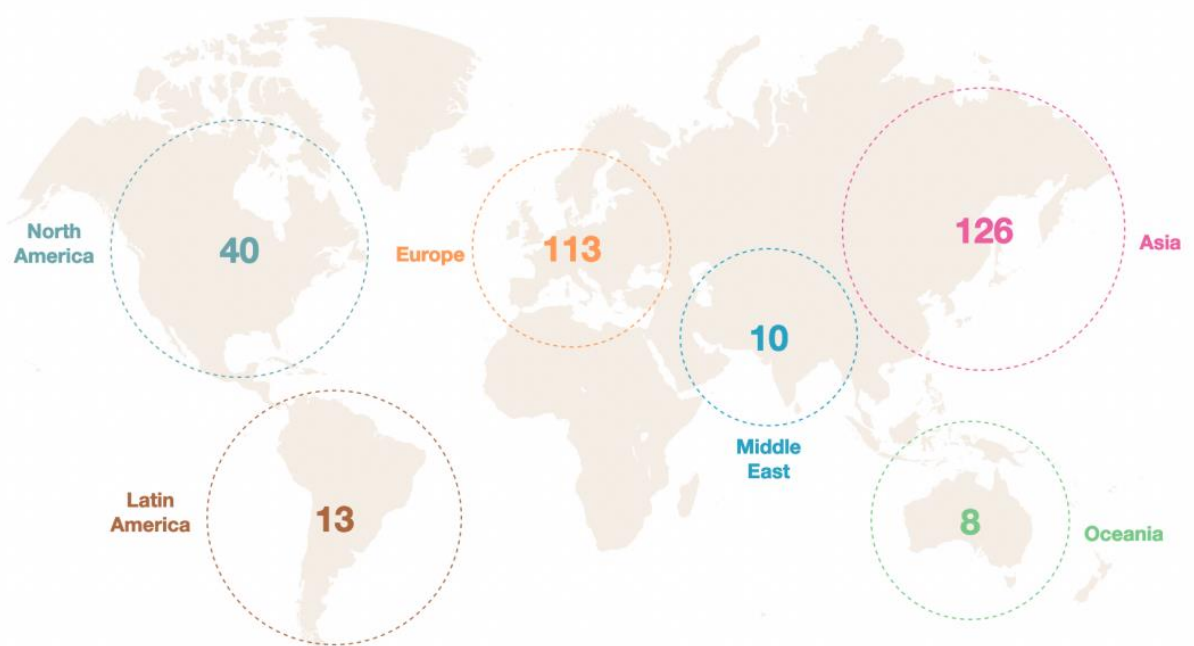

Figure 3. Global distribution map of Hermes stores

\section{PROMOTION}

The most important feature of Hermes promotions is that unlike other luxury brands, Hermes does not spend a lot of money on advertising their products. They do not have any brand ambassadors to promote their products for further marketing purposes. The way Hermes is promoted is also influenced to a large extent by the positioning of its products. Hermes is a unique, rare, luxury image, and because of this quality, Hermes does not need the same sales volume as other brands. As mentioned above, we can estimate that Hermes can make a profit of at least $80 \%$ on a single handbag, all Hermes needs to do is to capture its target sales group for quantitative sales. Hermes target groups are not only the wealthy at the top of society, but also for some royalty, using their use to promote and publicize the product. For example, Hermes' two most famous collections, Kelly and Birkin, were brought to attention and fame by the use of two celebrities, Grace Kelly and Jane Platinum respectively. This way of marketing is not only less expensive but also brings proof of rarity and preciousness to the target group, and can be very targeted to achieve the promotion purpose for the target group.

\section{CONCLUSION}

The products of Hermès itself use pure hand to make precious materials, with its tedious production process to determine its rarity. The expensive pricing determines the audience of Hermes and matches well with the exclusivity psychology of consumers. The active development of online channels promotes the sales of the products, while the wide distribution of stores allows consumers to have a better understanding of the products. The fact that Hermes does not have a lot of publicity also saves them a lot of money and does not affect the marketing of Hermes products.

\section{ACKNOWLEDGMENT}

Learning from the teachers, the author read a lot of literature in order to understand how to complete the thesis more effectively. This was a great challenge for me to write my dissertation, and I have acquired a lot of knowledge and skills through this attempt.

\section{REFERENCES}

[1] The Retrieval of Retrieved April 19, 2021 [J]. Retrieval of Retrieved April 19, 2021, Retrieved from

https://wenku.baidu.com/view/6dfbdfa3f08583d04 9649b6648d7c1c709a10b2f.html\#

[2] "Hermès - The Strategy Insights Behind The Iconic Luxury Brand." Martin Roll. 19 Mar. 2021. Web. 21 Mar. 2021.

[3] Luxury Resale Network. "The Amazing Quality and Craftsmanship Behind A Hermes Bag." Luxury Resale Network. Web. 21 Mar. 2021.

[4] "How Hermès Bags Are Made." Baghunter. Web. 21 Mar. 2021.

[5] "Hermes Leather Guide." Bags of Luxury Authentic Hermes Bags. Web. 21 Mar. 2021.

[6] "Hermès First Time Buyer Guide." Baghunter. Web. 21 Mar. 2021.

[7] "How Much Does It Cost Hermes to Manufacture a Birkin Handbag?" How Much Does It Cost Hermes 
to Manufacture a Birkin Handbag? Web. 21 Mar. 2021.

[8] Sabanoglu, Tugba. "Total Revenue of Hermès Worldwide 2020." Statista. 15 Mar. 2021. Web. 21 Mar. 2021.

[9]What is Premium pricing? . (n.d.). Retrieved April 19, 2021, from https://www.iiiff.com/article/374409

[10] "Hermès Online Channels Are Booming. Luxury Brands Should Take Note." Luxurysociety.com. Web. 21 Mar. 2021.
[11] "Hermes Marketing: Why People Spend $\$ 300,000$ on a Purse." Mktoolboxsuite.com. 30 Jan. 2021. Web. 21 Mar. 2021.

[12] Haque, Faizul, Richard Andrew, and The Strategy Watch. "Marketing Mix of Hermes or 4Ps." The Strategy Watch. 01 July 2020. Web. 21 Mar. 2021.

[13] "Stores - Group Overview - Hermès Financial Information." Stores - Group Overview - Hermès Financial Information. Web. 21 Mar. 2021.

[14] "Why Every Lady Needs an Hermès." Probutterfly. Web. 28 Mar. 2021. 